tions: evidence for viral compartmentalization and selection during sexual transmission. J. Virol. 70, 3098-3107 (1996)

4. Cameron, P., Pope, M., Granelli-Piperno, A. \& Steinman, R. M. Dendritic cells and the replication of HIV-1. Leukocyte Biol. 59, 158-171 (1996).

5. Spira, A.l. et al. Cellular targets of infection and route of viral dissemination after an intravaginal inoculation of simian immunodeficiency virus into rhesus macaques. J. Exp. Med. 183, 215-225 (1996).

6. Cameron, P.U. et al. Dendritic cells exposed to human immunodeficiency virus type-1 transmit a vigorous cytopathic infection to $\mathrm{CD}^{+}$cells. Science 257, 383-387 (1992)

7. Deng, $H$. et al. Identification of a major co-receptor for primary isolates of HIV-1. Noture 381, 661-666 (1996).

8. Dragic, T. et al. HIV-1 entry into $\mathrm{CD} 4^{+}$cells is mediated by the chemokine receptor CC-CKR-5. Nature
$381,667-673$ (1996).

9. Alkhatib, G. et al. CC-CKR-5: a RANTES, MIP-1a, MIP$1 b$ receptor as a fusion cofactor for macrophagetropic HIV-1. Science 272, 1955-1958 (1996).

10. Choe, $\mathrm{H}$. et al. The beta-chemokine receptors CCR3 and CCR5 facilitate infection by primary HIV-1 isolates. Cell 85, 1135-1148 (1996).

11. Doranz, B.J. et al. A dual-tropic primary HIV-1 isolate that uses fusin and the beta-chemokine receptors CKR-5, CKR-3, and CKR-2b as fusion cofactors. Cell 85, 1149-1158 (1996).

12. Feng, Y., Broder, C.C., Kennedy, P.E. \& Berger, E.A HIV-1 entry cofactor: functional CDNA cloning of a seven-transmembrane, $G$ protein-coupled receptor. Science 272, 872-877 (1996).

13. Granelli-Piperno, A. et al. Efficient interaction of HIV1 with purified dendritic cells via multiple chemokine receptors. J. Exp. Med. 184, 2433-2438 (1996).

14. Zaitseva, A. et al. Expression and function of CCR5 and CXCR4 on human Langerhans cells and macrophages: implications for HIV primary infection. Noture Med. 3, 1369-1375 (1997).

15. Weissman, D. et al. Macrophage-tropic HIV and SIV envelope proteins induce a signal through the CCR5 chemokine receptor. Nature 389, 981-984 (1997).

16. Blauvelt, A. et al. Productive infection of dendritic cells by HIV-1 and their ability to capture virus are mediated through separate pathways. J. Clin. Invest. $100,2043-2053$ (1997).

Laboratory of AIDS Immunopathogenesis

Department of Medicine

Division of Infectious Diseases

Centre Hospitalier Universitaire Vaudois

1011 Lausanne, Switzerland

\title{
Rats go with the (urine) flow
}

\section{A new study describes the correction of a rat model for inherited diabetes insipidus by gene therapy in the central} nervous system (pages 1402-1404).

$T^{+}$ HE DISORDER DIABETES insipidus may seem an unlikely context in which ideas about possible gene therapy strategies for brain disorders may be first tried. However, the Brattleboro strain of rats - which has inherited diabetes insipidus ${ }^{1}$ — has been used repeatedly in neuroendocrinology as a unique resource, and, once again, its merits as an experimental model have been extended. On page 1402 of this issue, Geddes et al..$^{2}$ describe their studies to test the usefulness of adenovirus-based vectors for the long-term correction of a defect in the central nervous system (CNS).

By way of background, the defect in Brattleboro rats has been characterized as a recessive hypothalamic diabetes insipidus, arising from the loss of a single base-pair in the gene for the precursor protein (prepro-AVP) that encodes arginine vasopressin (AVP) and its homologous carrier protein, neurophysin-II (ref. 3). These rats show copious urine production and concomitant water intake, due to a lack of AVP. But, surprisingly, the pre-pro-AVP gene is normal in exon 1 (which encodes arginine vasopressin). The deletion occurs in the middle of exon 2, within the sequence of neurophysin-II. The resulting frame shift leads to an extended open reading frame which continues through the normal stop codon, creating a poly-lysine tail. This mutant prepro-AVP cannot be normally processed, and accumulates in the endoplasmic reticulum, preventing the production, packaging and eventual secretion of AVP (ref. 4).

The direct relevance of the Brattleboro model for human diabetes insipidus is limited. Inherited forms of the human disease are caused by several identified genes

\section{Michael R. HANley}

including, predominantly, the AVP V2receptor, which is expressed in the kidney ${ }^{5}$. However, although rare, an inherited human diabetes insipidus has arisen from a neurohypophyseal origin ${ }^{6}$. The true importance of the work by Geddes et al. is in testing crucial features of a gene therapy strategy for the brain: the suitability of the vector; the selectivity of transgene expression; and the persistence of therapeutic efficacy. The Brattleboro model is ideal for this, because the aim herein is to reverse a lossof-function single gene change in the brain-a much simpler circumstance than in complex idiopathic CNS disorders such as Alzheimer's disease. Moreover, the consequences can be readily measured noninvasively (for example, by urine production and thirst).

Geddes et al. injected the adenoviral expression vector, encoding a synthetic gene for the open reading frame of rat prepro- $A V P$, into the supraoptic nucleus in the hypothalamus of the rat brain. One gratifying (but as-yet unexplained) aspect is that, although the transgene could be expressed as a messenger RNA when injected into a control brain region, it was not processed to functional AVP peptide. This unexpected advantage may arise from a self-selection process. Inappropriate cell types could, perhaps, lack the contextual cues in vivo to support biosynthesis of an endocrine signal. But whether this will prove to be true for other types of transgenes in other contexts remains to be seen.

A single injection of the gene therapy vector led to a substantial ( $25-45$ percent) recovery of normal antidiuretic functions, which was long lasting (up to four months after treatment) and, apparently, without side-effects. The question of possible sideeffects will, however, be a crucial issue for further investigation. Adenovirus vectors used for transducing transgenes into the brain have been linked to induction of cell death (reviewed in ref. 7). Thus, the loss of cells from the regions of the CNS that express the adenovirus-encoded gene will need to be carefully assessed. Nevertheless, the results of Geddes et al. are an optimistic milestone in the development of CNS gene therapy.

1. Valtin, $H$. Hereditary diabetes insipidus in rats (Brattleboro strain). Am. J. Med. 42, 814-827 (1967).

2. Geddes, B.J., Harding, T.C., Lightman, S.L. \& Uney, I.B. Long-term gene therapy in the CNS: reversal of hypothalamic diabetes insipidus in the Brattleboro rat by using an adenovirus expressing arginine vasopressin. Nature Med. 3, 1402-1404 (1997).

3. Schmale, $H$. \& Richter, D. Single base deletion in the vasopressin gene is the cause of diabetes insipidus in Brattleboro rats. Nature 308, 705-709 (1984).

4. Ivell, R., Burback, P.H. \& Leeuwen, F.W. The molecular biology of the Brattleboro rat. Front. Neuroendocrinol. 4, 313-338 (1990).

5. Sharif, M. \& Hanley, M.R. V2-vasopressin peptide receptors. Nature 357, 279-280 (1992).

6. Rutishauer, I. et al. A novel point mutation in the translation initiation codon of the pre-provasopressin-neurophysin-Il gene. /. Endocrinol. Metab. 81, 192-198 (1996).

7. Peltekian, E. et al. Adenovirus-mediated gene transfer to the brain: methodological assessment. 1. Neurosci. Meths 71, 77-84 (1997).

Department of Biological Chemistry

UCD School of Medicine

Tupper Hall

Davis California 95616-8635, USA 